\title{
Development of a Reinforced Concrete Sheet Pile Wall Element
}

\author{
Kristóf Lődör ${ }^{1 *}$, János Szendefy ${ }^{1}$, Olivér Kovács² ${ }^{2}$ Zsombor Illés \\ ${ }^{1}$ Department of Engineering Geology and Geotechnics, Faculty of Civil Engineering, Budapest University of Technology and \\ Economics, H-1111 Budapest, Müegyetem rkp. 3., Hungary \\ 2 EFERTE Ltd., H-1111 Budapest, Budafoki u. 10/b. \\ *Corresponding author, e-mail: lodor.kristof@epito.bme.hu
}

Received: 02 January 2020, Accepted: 11 February 2020, Published online: 12 March 2020

\begin{abstract}
In the forthcoming years intensive renovation and reconstruction works can be expected on the banks' freshwaters of Hungary. For the rehabilitation of the shores of Lake Velence works are starting in 2020. To support these investments there has been a demand for prefabricated reinforced concrete sheet pile walls. Realizing the opportunity, a major player in the market of prefabricated reinforced concrete elements for water way construction, CSOMIÉP Ltd. decided to develop a reinforced concrete sheet pile wall. In this study the development and complex structural and geotechnical design concept are shown through the major structural behaviors and useable geometries.
\end{abstract}

Keywords

sheet pile wall, embankment protection, prefabricated concrete element, plaxis 3D, plaxis 2D, numerical modelling, stability analysis

\section{Introduction}

In the forthcoming years intensive renovation and reconstruction works can be expected on the banks' freshwaters of Hungary. For the rehabilitation of the shores of Lake Velence works are starting in 2020. Furthermore, there are several Balaton harbors construction or refurbishment is also expected [1]. To support these investments there has been a demand for prefabricated reinforced concrete sheet pile walls. The availability of these type of retaining walls in Hungary is limited. Realizing the opportunity, a major player in the market of prefabricated reinforced concrete elements for water way construction, CSOMIÉP Ltd. decided to develop a reinforced concrete sheet pile wall.

The primary consideration in developing the new product line was technical efficiency, but even in an urban setting aesthetic appearance of the sheet pile wall elements is necessary. The CSOMIÉP Ltd. has invited engineers and companies with expertise in various fields, to participate in the development, thanks to which the developed product has been optimized for geotechnical, static, concrete technology and design aspects [2].

It was a great honor for us to be invited to the developers' team and got to know each other. It was fascinating opportunity to work together with many excellent professionals. Our article briefly summarizes the geotechnical aspects of the development procedure.

\section{Design considerations}

It was an important aspect of the design procedure that the element should have an aesthetic appearance as these elements might be used in a city or in a frequented tourist area. The design should not resemble the commonly used industrial steel sheet pile wall. However, the final layout of the element is governed by static considerations. The structural design work was led by Olivér Kovács (head of the structural engineering team at EFERTE Ltd.), who optimized the inertia of the sheet pile wall element. The other important question was the arrangement of the reinforcement in an efficient way, based on these two criteria, a cross-section shape with a rear reinforcing rib and a relatively thin front panel was chosen.

After the static design phase, the element had the same cross-section along its entire length. For geotechnical considerations the rear rib was extended below the front panel, similar to a solider pile wall (Berlin wall). To invoke the deeper soil layers in the force distribution, as they might be in better condition than the upper layers. The extended rib is not only efficient, because of the reduction in the use of concrete, but it is also advantageous for the installation (driven) of the sheet pile wall element. The extended rib makes the hammering or vibration of the element easier during construction. A cast-in-place rein- 
forced concrete bulkhead cap is required to structurally tie the tops of the concrete sheet piles together and to provide corrosion protection.

The designed, relatively flat surface provides a good opportunity for different surface textures and prints. The elements placed side by side will provide a slightly wavy surface in a way similar to the water surface. This appearance apart from aesthetic considerations, also has a static role.

\section{Geotechnical numerical modelling}

Plaxis 3D geotechnical software was used for the stability and deformation analysis of the components and the system. The use of a 3D finite element software was chosen, because of the variety of cross-sections and spacing of the elements $[3,4]$.

In classical soil mechanics, the factor of safety is the ratio of the shear strength at the plane of potential failure $\tau$ f and the shear stress action in the same plane $\tau$, namely

$F S=\frac{\tau_{f}}{\tau}=\frac{c+\sigma_{n} \times \tan (\varphi)}{\tau}$.

The soil conditions in case of the model are accordingly to a geotechnical report from the shore of Lake Velence.

The soil stratification and parameters are characteristic for the more critical zones. If the stability and the deformations of the structure are acceptable, it is likely that in case of sites with more favorable geotechnical conditions will be also reasonable. The system can be optimized for each site. During the description of the heterogeneous soil environment such as the following soil layers were defined; artificial fill, soft organic soil layers sensitive to compression were. Fig. 1. shows a soil stratification examined during modelling.

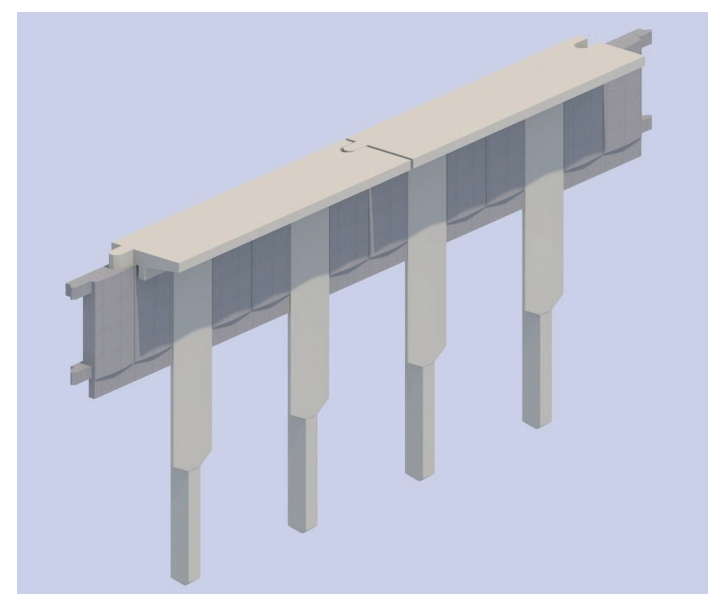

Fig. 1 One of the studied structural geometry
In finite element calculations the behavior of soil layers can be defined by different material models (there are also built-in and user defined material models). It is well known that soil behavior is nonlinear, and the deformations are influenced by many factors. Taking this into account, there are various material models are available. The one that is used in our finite element calculations is the HSSmall (Hardening Soil with Small Strain Stiffness - HSS) material model (Fig. 2) [5]. This material model considers the average increase in stiffness with increasing normal stresses, the changes in shear stresses induced volume change, also takes into account that the stiffness of the soil increases significantly in the range of small deformations. In term of real 3D simulation of the investigated structure, the sheet pile wall elements were defined as volume elements $[6,7]$. The properties of the investigated soil profile are summarized in Table 1.

The groundwater level was assumed to be the same as the water level in the lake bed, which depends on the meteorological conditions. Calculations were made for the cases, when the groundwater level is on the surface, $0.50 \mathrm{~m}$ below and $1.00 \mathrm{~m}$ below the surface. Furthermore,

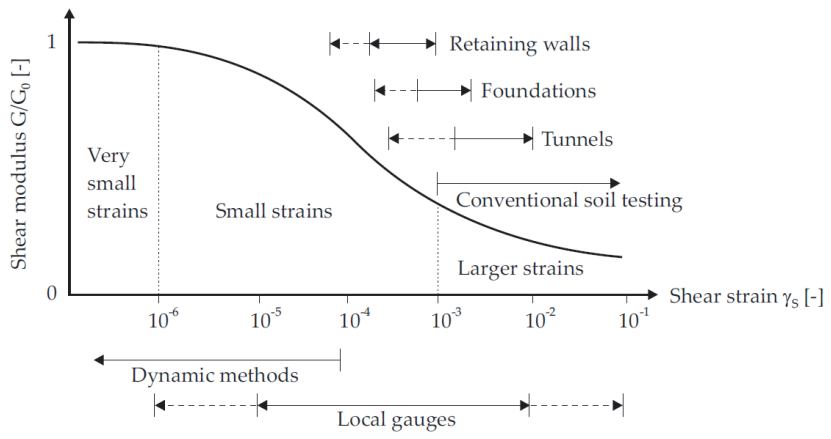

Fig. 2 Characteristic stiffness-strain behavior of soil with typical strain ranges for laboratory tests and structures [5]

Table 1 Material properties

\begin{tabular}{lccccc}
\hline Properties & Silt & Peat & LP clay & Sandy silty & HP clay \\
Material model & HSS & HSS & HSS & HSS & HSS \\
\hline$g_{\text {unsat }}\left(\mathrm{kN} / \mathrm{m}^{3}\right)$ & 18.5 & 7.5 & 18.5 & 18.5 & 19.5 \\
$g_{\text {sat }}\left(\mathrm{kN} / \mathrm{m}^{3}\right)$ & 18.5 & 7.5 & 18.5 & 18.5 & 19.5 \\
$E_{\text {oed }}{ }^{\text {ref }}(\mathrm{MPa})$ & 8 & 1 & 7 & 8 & 6 \\
$E_{50}{ }^{\text {ef }}(\mathrm{MPa})$ & 8 & 1 & 7 & 8 & 6 \\
$E_{\text {ur }}{ }^{\text {ref }}(\mathrm{MPa})$ & 24 & 3 & 21 & 24 & 18 \\
$m(-)$ & 0.75 & 0.75 & 1.00 & 0.60 & 1.00 \\
$\phi^{\prime}\left({ }^{\circ}\right)$ & 19.1 & 5.7 & 18.0 & 19.1 & 14.3 \\
$g_{0.7}(-)$ & $210-4$ & $210-4$ & $210-4$ & $210-4$ & $210-4$ \\
$G_{0}{ }^{\text {ref }}(\mathrm{MPa})$ & 90 & 12.5 & 85 & 90 & 74.5 \\
$R_{\text {int }}(-)$ & 0.67 & 0.67 & 0.67 & 0.67 & 0.67 \\
\hline
\end{tabular}


it was analyzed in the case of potential backflow, when the water level of the lake is lower than the groundwater level [8]. In the numerical calculations, using Plaxis 3D, 15-noded wedge finite elements are used. The 3D model geometry is presented in Fig. 3.

\section{Modelling of structural elements}

During the development of the sheet pile wall elements, the geotechnical models used the geometrical, material and stiffness parameters from structural designers' model (Fig. 4). After the geotechnical finite element analysis, the effects and displacements acting on the structure were transformed to the structural model, which was created using Axis VM finite element software, which is a widespread (especially in Hungary) special finite element software for structural engineers [9]. After a few rounds of iteration, which approximately means a few hundred hours of modelling a configuration, which can be said to be optimum was reached.

Prefabricated reinforced concrete structural elements, during the numerical modelling, were defined as a solid watertight volume element, with linearly elastic material model. Because of its "meticulousness", real geometry due to mesh generation problems could not be used in the finite element software, so an idealized cross-section was defined with the same moment of inertia and its cross-sectional area as the real cross-section, so the structural behavior can be properly modelled and evaluated.

The volume element concept which is a well-known and widespread modelling process for modelling of foundations corresponds to a full discretization of structural elements using 3D finite elements. This process allows a precise, complex modelling of the structural geometry, which

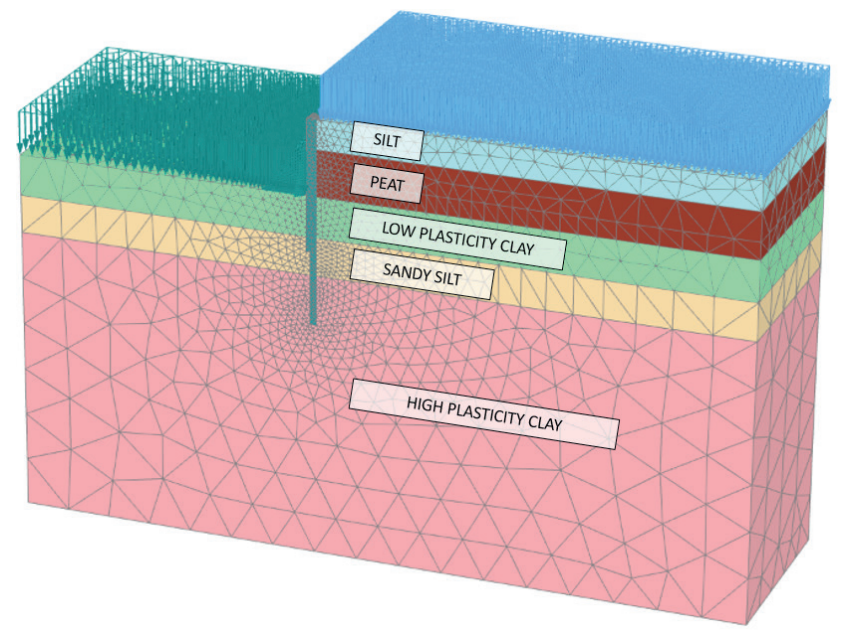

Fig. 3 3D finite element model geometry
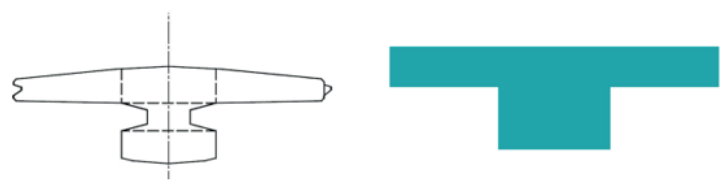

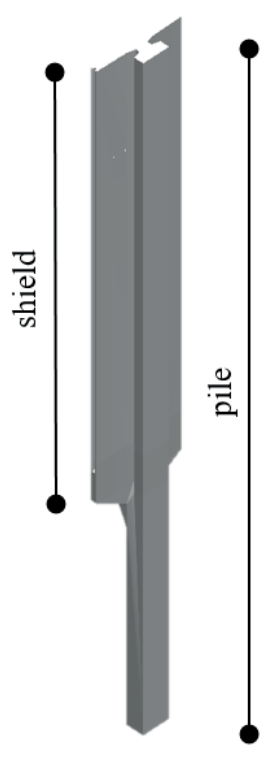

(a)

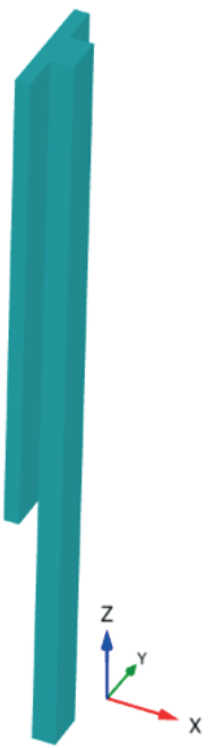

(b)
Fig. 4 Sheet pile wall element in Axis VM (a); the same element in Plaxis 3D (b)

is a very important question for real simulation of sheet pile wall-soil interaction along the shaft of the pile and the shield. The soil-structure contact is modelled with interface elements with zero thickness. Elastic-plastic model is used to describe the behavior of interface for the modelling of soil-structure interaction. The Coulomb criterion is used to distinguish between elastic behavior, where small displacements can occur within the interface, and plastic interface behavior when permanent slip may occur. The elastic zone is limited by value of the maximum shear stress $\tau$ which can be mobilized at the contact of the shaft and the soil. Normal stresses in the soil are also limited by tension cut-off criterion. The most important interface property is the strength reduction factor $\left(R_{\text {inter }}\right)$ which was 0.90 during the simulations. The interface properties are calculated from the soil properties in the associated data set and the strength reduction factor.

There are many variations available from the catalogue of the reinforced concrete sheet pile walls. With the combination of the elements an economical and safe shore support can be constructed. It is possible to place the sheet pile wall elements continuously (side by side) to form a closed pile wall or to place the sheet pile wall elements further apart or just place every second one, between the piles prefabricated reinforced concrete planks just like a 
solider pile wall (Berlin wall) can be placed. Every possible formation was examined using Plaxis 3D finite element software, as well as the results of the 3D geotechnical software were transferred back to the reinforced concrete structures in AXIS VM numerical software.

\section{Geotechnical calculations}

During the calculations, sheet pile walls with different geometry were analyzed. The deformation and the safety factor for stability of the different configurations vary, even in a soil environment with critical or low shear strength, with compaction sensitive soil layers.

The supportive effect of the lake- and river-beds by creating a slope at the shore was taken into account (Fig. 5.) [10]. At the encounter of the structural elements and the bed of the water body, based on our previous experiment's presence of $1.00 \mathrm{~m}$ and $2.00 \mathrm{~m}$ high wedges were defined. In the case of the designed sheet pile wall, there is a possibility to anchor them with geogrid elements [11,12], which favorable effect on against displacements and global stability can be justified with spatial finite element modelling.

There are several types of structural geometry so it is possible to use the reinforced concrete sheet pile wall with full length shield (to mobilize the passive earth pressure as

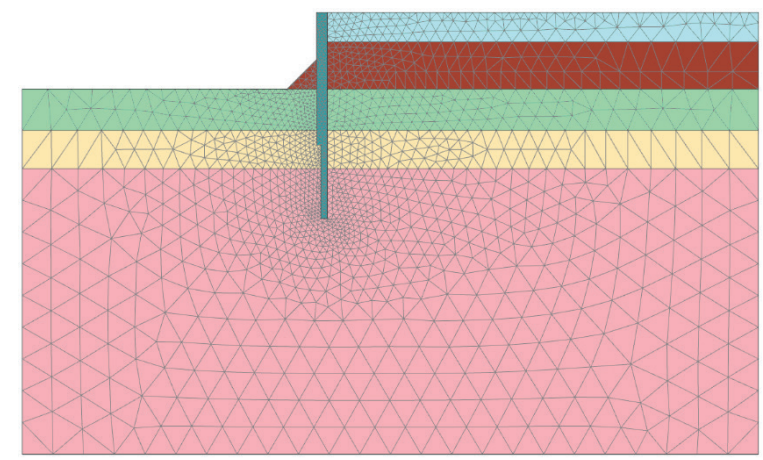

(a)

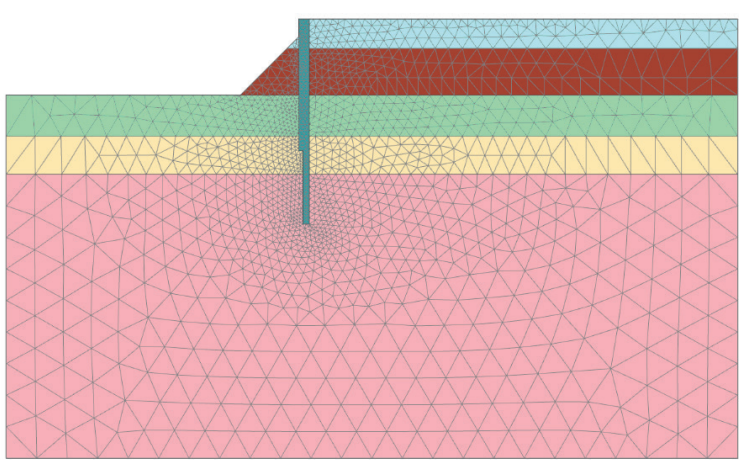

(b)

Fig. 5 Slope at the bed of the water body $-1.00 \mathrm{~m}$ high supporting soil wedge (a); $2.00 \mathrm{~m}$ high supporting soil wedge (b) much as we can) or to optimize the shield and pile ratio if the soil profile allows it. With numerical calculations the shape and geometry of the structural elements were investigated.

\section{Evaluation of the geotechnical numerical modelling results}

In this paragraph, the results of some modelled structural and bed designs are presented. In case of them the operation of the support system is clearly visible as well as the most influential effects on the structure's displacements and stability.

In Fig. 6 a diagram of the displacements of a $7.00 \mathrm{~m}$ long sheet pile wall element is visible (surface load is $10 \mathrm{kPa}$ ). The shield and pile ratio of the element was defined before the calculation $(3.50 \mathrm{~m}$ shield and 3.50 , pile as well as $4.50 \mathrm{~m}$ shield and 2.50 pile). The figure shows that if necessary, the increased shield length may increase the passive earth pressures as well as the resistance and on the other hand, due to the increase of resistance the displacements are reduced effectively. That can be a very economical and effective solution to use longer pile section on the sheet pile wall element if the bearing soil layers are deep from the river bed.

In Figs. 7 and 8, the effect of the sloping bed with different shield and pile ratio for displacements and for global stability are visible. It can be observed that with 1.00 meter of wedging a $20 \%$ reduction is already observed in the deformations. While with a wedge of 2.00 meters the reduction

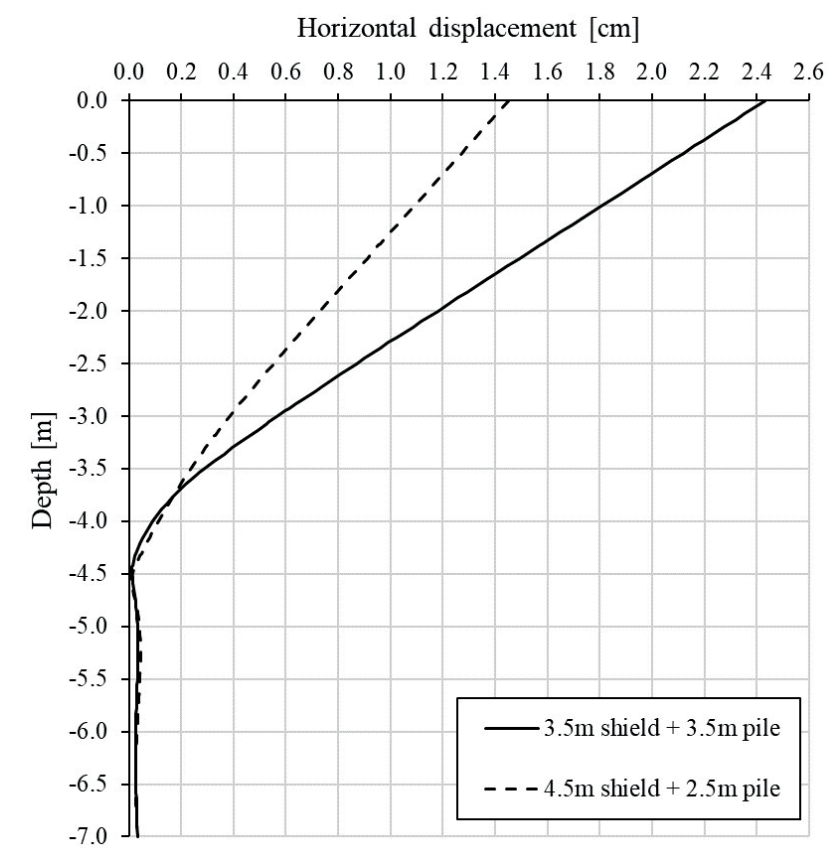

Fig. 6 Effects of the change in length of shield and pile on the displacements of a $7.00 \mathrm{~m}$ long sheet pile wall 


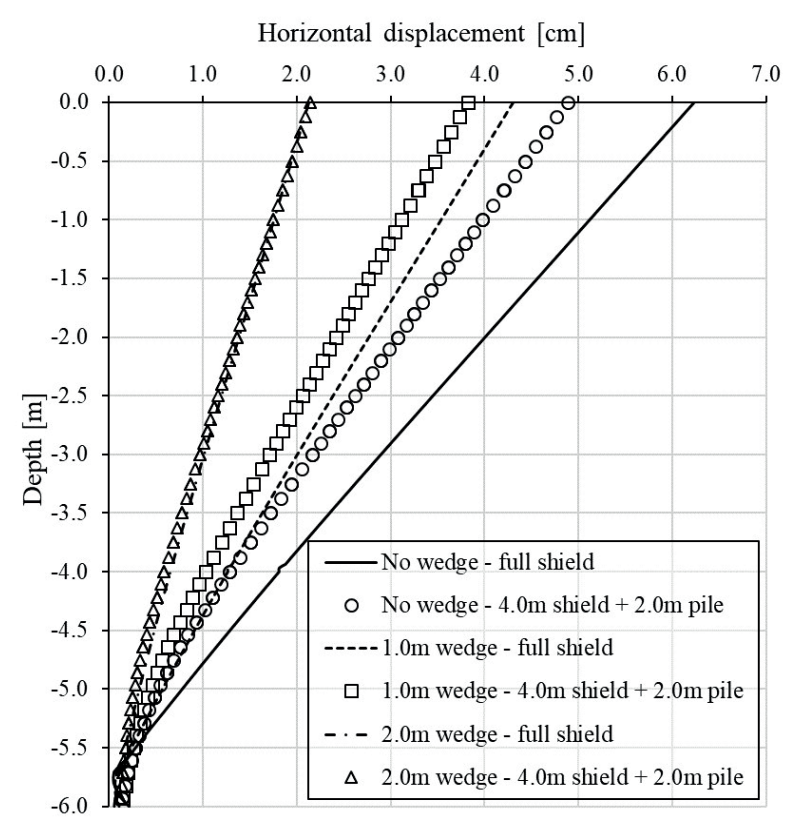

Fig. 7 Supporting effect of sloping bed bottom on structural displacements

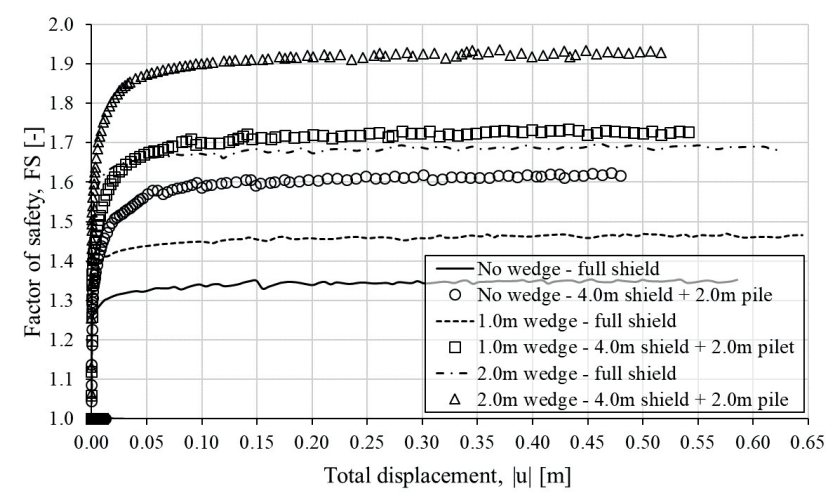

Fig. 8 Supporting effect of sloping bed bottom on stability

is already $60 \%$. There are significant difference in maximum displacements, but also there is a huge influence on the curvature of the structural elements and thus in their stresses. A similar trend is observed in global stability of the supporting slope/ground mass as the passive earth resistance increases, which acts as a stabilizing force within the system's force distribution. These results show that during modelling, if the natural supportive effect of bed slope is ignored the calculations can result significantly larger deformations. The expectation of larger deformations and smaller stabilizing forces that can result in the oversize the structural elements and can lead to underutilization.

\section{Comparison of 2D and 3D geotechnical simulations}

If complex spatial numerical calculation is not possible due to technical limitations, a potential and affordable solution could be using 2D geotechnical software to solve the design problems. Plaxis 2D finite element analyses were performed to compare the $3 \mathrm{D}$ and $2 \mathrm{D}$ calculation results and to check the advantages and disadvantages of the plane strain simulation of the sheet pile wall structural element [13].

Using Plaxis 2D there is no possibility of complex, precise geometric examination, in this case the sheet pile wall element is replaced by a 2D plate element. Plates which are actually beam elements, are structural objects used to model slender structures in the ground with a significant flexural rigidity (or bending stiffness) and a normal stiffness. Plates can be used to simulate the influence of walls, plates, shells or linings extending in z-direction. The most important plate parameters are the flexural rigidity (bending stiffness) EI and the axial stiffness EA. From these two parameters an equivalent plate thickness $d_{e q}$ is calculated from the following equation (Eq. (2)):

$d_{e q}=\sqrt{12 \frac{E I}{E A}}$

Plates in the 2D finite element model are composed of beam elements (line elements) with three degrees of freedom per node: two translational degrees of freedom $\left(u_{x}, u_{y}\right)$ and one rotational degrees of freedom (rotation in the x-y plane: $\phi_{z}$ ) [14].

Fig. 9 shows the horizontal displacement of the reinforced concrete sheet pile wall $(4.50 \mathrm{~m}$ shield $+2.50 \mathrm{~m}$ pile section) in term of $2 \mathrm{D}$ and $3 \mathrm{D}$ finite element calculations (surface load is $5 \mathrm{kPa}$ ). As it can be seen in Fig. 9 and Fig. 10 the maximum horizontal displacement of the sheet pile wall is $4.83 \mathrm{~mm}$ with $3 \mathrm{D}$ numerical simulation,

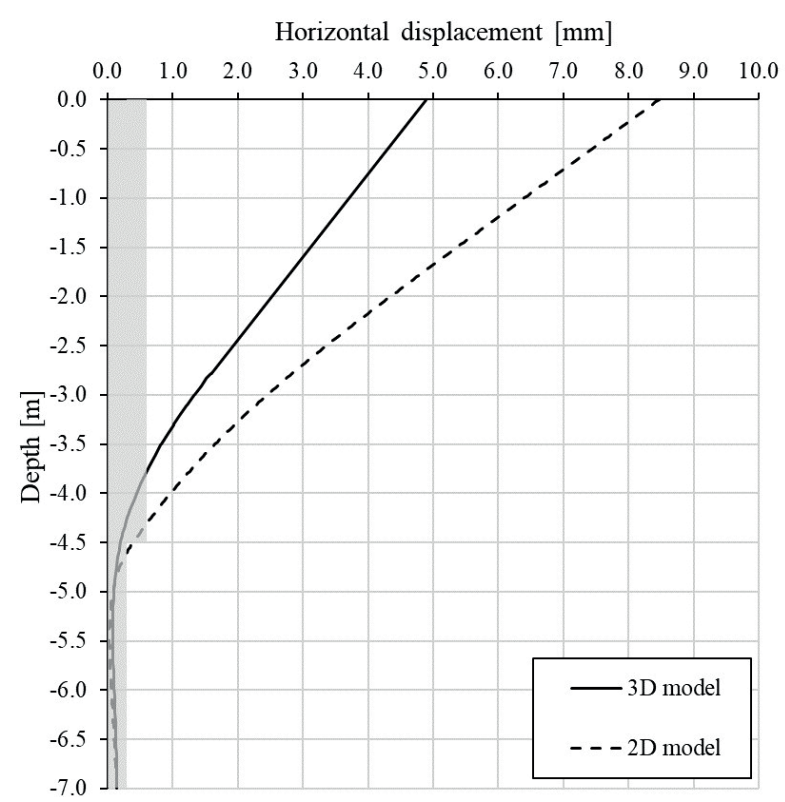

Fig. 9 Horizontal displacement in case of 2D and 3D simulations 


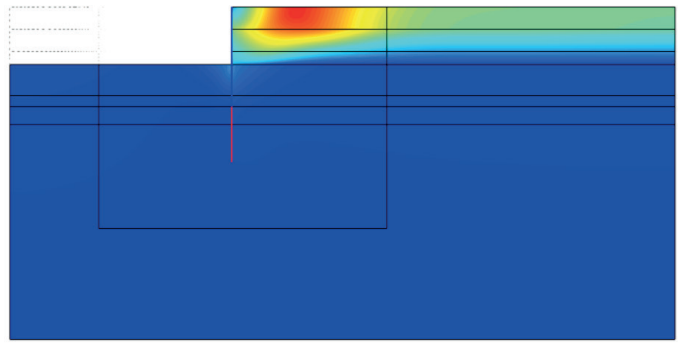

(a)

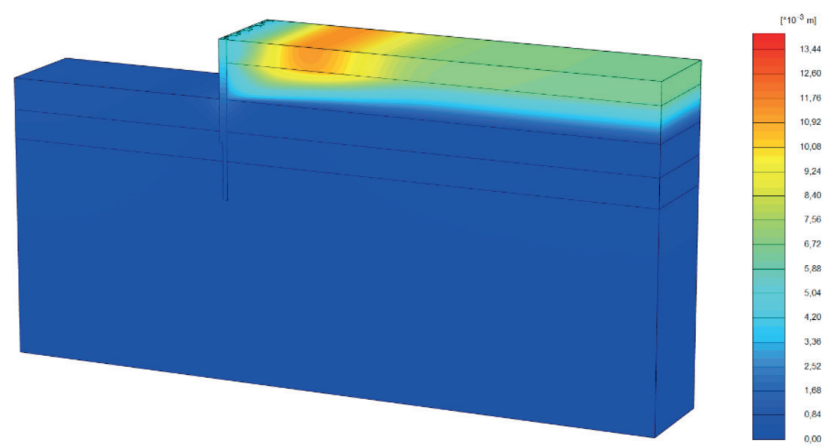

(b)

Fig. 10 Total displacements - 2D model (a); 3D model (b)

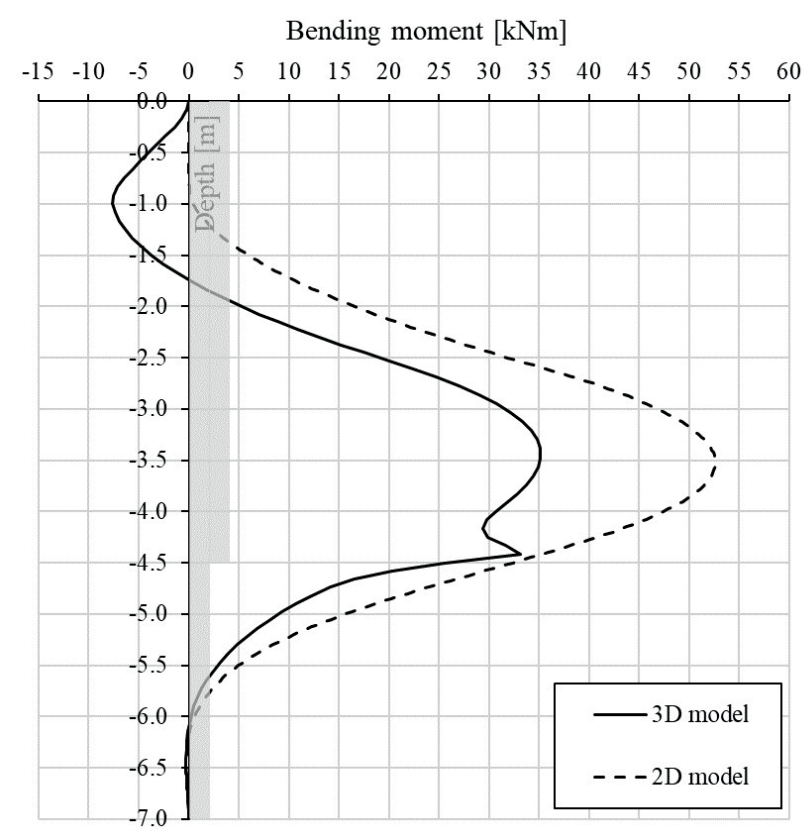

Fig. 11 Bending moments with 2D and 3D finite element calculations

on the other hand using 2D simplified model, the total horizontal deformation is $8.47 \mathrm{~mm}$ which is 1.75 times higher than with 3D modelling. If we look at Fig. 11, where the bending moments are shown along the depth comparing the 2D and 3D simulation results, we can observe that with $2 \mathrm{D}$ simplification the maximum bending moment is 1.50 times higher than with $3 \mathrm{D}$ modelling thanks to the higher curvature in the deformed shape of the investigated element.

These statements mean that the 2D simplified models give a great opportunity to examine the behavior of the investigated soil-structure interaction and to run several models in a short time in pre-design phase, but in term of detailed design procedure the 3D numerical calculation and full geometrical discretization of the complex wall element is inevitable in order to get an economical and effective structural element. In 2D simulations the definition of the sheet pile wall with plate element cannot reach appropriate and accurate structural stiffness so this is the reason why higher deformations have been developed.

\section{Structural calculations}

Nowadays, during the calculations, the design method of foundations, retaining walls are based on modulus of subgrade reaction (Winkler theory). The soil-structure interaction is replaced by springs, where the deformation is the function of the bearing pressure and spring force. The spring force depends on the load, the load distribution, the stiffness of the structure and the deformation properties of the subsoil. The modulus of subgrade reaction is not a constant value or a soil property, its value changes from point to point on the structures. In Hungary the structural elements are designed with special structural engineering software where the input modulus of subgrade reactions are usually calculated with geotechnical engineering software (especially the deformation of the structure).

During the whole design and development method of this reinforced concrete sheet pile wall element, the structural and geotechnical engineers work together and they always share the results of their numerical simulations because the input parameters in case of the geotechnical calculations are the structural loads, the designed geometry and the soil profile on the other hand in term of structural calculations the input parameters are the modulus of subgrade reaction, the earth pressures and real soil-structure interaction behavior so the deformation shape of the structural elements. For the successful and optimal design of the sheet pile wall there were several iteration round between the structural and geotechnical engineers to reach the same structural behavior (deformations and stresses) in the geotechnical and structural engineering software. The deformation results and the rein-forcement of the structural element are presented in Fig. 12. 


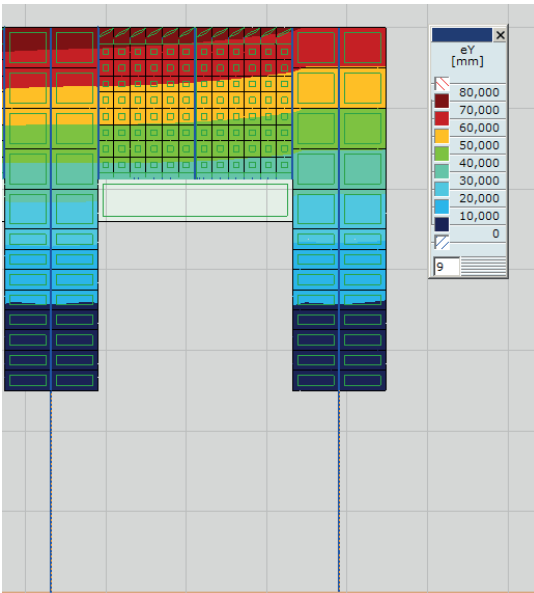

(a)

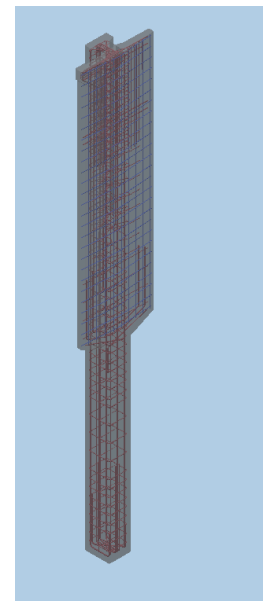

(b)
Fig. 12 Results of the structural design - Deformation (a); Reinforcement (b)

\section{Conclusions}

Today, there is an increasing social demand in Hungary for freshwater protection and to involve them more actively in our living space. One of the main usage of the newly developed sheet pile wall element can be the construction of coast guard structures, which can help prevent erosion, as well as provide places for sport activities such as marinas and other recreational areas such as promenades along the riverbanks.

The prefabricated concrete sheet pile wall, that was developed last year, meant to serve these goals. During the development of the product line geotechnical, structural,

\section{References}

[1] Wall, H., Wadsö, L."Corrosion rate measurements in steel sheet pile walls in a marine environment", Marine Structures, 33, pp. 21-32, 2013.

https://doi.org/10.1016/j.marstruc.2013.04.006

[2] Hoang, T. V., Chou, T. Y., Fang, Y. M., Ngo, C. P., Pham, N. B. "Design and Construction Concrete Sheet Piles for the Riverine Embankment Work in Mekong River Delta, Vietnam", International Journal of Engineering Innovation and Research, 8(1), pp. 59-67, 2019. [online] Available at: http://www.ijeir.org/ index.php/issue? view $=$ publication $\&$ task $=$ show $\&$ id $=747$ [Accessed: 5 February 2020]

[3] Doubrovsky, M. P., Meshcheryakov, G. N. "Physical modeling of sheet piles behavior to improve their numerical modeling and design", Soils and Foundations, 55(4), pp. 691-702, 2015.

https://doi.org/10.1016/j.sandf.2015.06.003

[4] Szepesházi, A., Mahler, A., Móczár, B. "Three Dimensional Finite Element Analysis of Deep Excavation' Concave Corners", Periodica Polytechnica Civil Engineering, 60(3), pp. 371-378., 2016.

https://doi.org/10.3311/PPci.8608 concrete technology and construction aspects were taken into account. It resulted in a technically effective as well as an aesthetic structure.

When developing the product line, geotechnical conditions were modelled according to the ones usually found at the freshwater shores. These unfavorable geotechnical stratifications include the presence of organic and soft soils. With the elongation of the rib, deeper and more favorable layers have been involved in the force distribution. 3D finite element modelling is becoming more and more widespread in geotechnics, for the calculations of earth and water pressure as well as deformations in case of structures with nonuniform cross-sections. Thanks to the use of 3D modelling, the structural designers could apply more approximate boundary conditions, which allowed them to optimize the structures. 2D simplified models give a great opportunity to examine the behavior of the investigated soil-structure interaction and to run several models in a short time in pre-design phase, but in term of detailed design procedure the $3 \mathrm{D}$ numerical calculation and full geometrical discretization of the complex wall element is inevitable in order to get an economical and effective structural element.

The technical novelty and success of the product development is demonstrated by the fact that the prefabricated reinforced concrete sheet pile wall product line has become a copyrighted industrial product. At the year of 2017 the product received the Hungarian Product Grand Prize.

[5] Benz, T. "Small-Strain Stiffness of Soils and its Numerical Consequences", PhD Dissertation, University of Stuttgart, 2007. [online] Available at: https://www.igs.uni-stuttgart.de/dokumente/ Mitteilungen/55 Benz.pdf [Accessed: 5 February 2020]

[6] Plaxis "Plaxis 3D Anniversary Edition" [online] Available at: https://www.plaxis.com/support/manuals/plaxis-3d-manuals/ [Accessed: 5 February 2020]

[7] Rémai, Zs. "Correlation of undrained shear strength and CPT resistance", Periodica Polytechnica Civil Engineering, 57(1), pp. 39-44, 2013.

https://doi.org/10.3311/PPci.2140

[8] Koltuk, S., Azzam, R. "Design Charts for Circular-Shaped Sheeted Excavation Pits against Seepage Failure by Heave", Periodica Polytechnica Civil Engineering, 60(3), pp. 421-426, 2016. https://doi.org/10.3311/PPci.8522

[9] Chogueur, A., Abdeldjalil, Z., Reiffsteck, P. "Parametric and Comparative Study of a Flexible Retaining Wall", Periodica Polytechnica Civil Engineering, 62(2), pp. 295-307, 2018. https://doi.org/10.3311/PPci.10749

[10] Julien, P. Y. "Sedimentation and Erosion", Cambridge University Press, Cambridge, UK, 2010. https://doi.org/10.1017/CBO9780511806049 
[11] Bilgin, Ö. "Numerical studies of anchored sheet pile wall behaviour constructed in cut and fill conditions", Computers and Geotechnics, 37(3), pp. 399-407, 2010. https://doi.org/10.1016/j.compgeo.2010.01.002

[12] Detert, O., Wehrli, E. "Flexible high modulus geogrid used as a tie-back anchors for retaining structures", In: 11th Baltic Sea Geotechnical Conference, Geotechnics in Maritime Engineering, Gdansk, Poland, 2008, pp. 43-47. [pdf] Available at: https://www, huesker.nl/fileadmin/Media/Scientific_Revised_Paper/P512 Flexible_high_modulus_geogrids_used_as_tie-back_anchors for_retaining_structures.pdf [Accessed: 5 February 2020]
[13] Jesmani, M., Mehdipour, I., Ajami, A. "Comparison between 2d and $3 \mathrm{~d}$ behavior of sheet piles by finite element method", Kuwait Journal of Science and Engineering, 38(2B), pp. 1-14, 2011.

[14] Plaxis "Plaxis 2D Reference Manual, Anniversary Edition" [pdf] Available at: file:///C:/Users/user/Downloads/2D-2-Reference\%20 (2).pdf [Accessed: 5 February 2020] 